\title{
EVALUATING VIBRATIONS ON A SMALL-SCALE MODEL OF A TIMBER FOOTBRIDGE
}

\author{
Pedro Gutemberg de Alcântara Segundinho ${ }^{1}$, Antonio Alves Dias ${ }^{2}$, Marcelo Rodrigo Carreira $^{3}$
}

\begin{abstract}
In Brazil, the study of pedestrian-induced vibration on footbridges has been undertaken since the early 1990s, for concrete and steel footbridges. However, there are no recorded studies of this kind for timber footbridges. Brazilian code ABNT NBR 7190 (1997) gives design requirements only for static loads in the case of timber footbridges, without considering the serviceability limit state from pedestrianinduced vibrations. The aim of this work is to perform a theoretical dynamic, numerical and experimental analysis on simply-supported timber footbridges, by using a small-scale model developed from a $24 \mathrm{~m}$ span and $2 \mathrm{~m}$ width timber footbridge, with two main timber beams. Span and width were scaled down (1:4) to $6 \mathrm{~m}$ e $0.5 \mathrm{~m}$, respectively. Among the conclusions reached herein, it is emphasized that the Euler-Bernoulli beam theory is suitable for calculating the vertical and lateral first natural frequencies in simply-supported timber footbridges; however, special attention should be given to the evaluation of lateral bending stiffness, as it leads to conservative values.
\end{abstract}

Keywords: Timber footbridges, pedestrian-induced vibrations, serviceability limit state, small-scale model.

\section{INTRODUCTION}

Civil engineers have long been aware of the problems caused by the excessive vibrations that cause the resonance phenomenon on footbridges. The causal sources of this phenomenon are many, with different possible aspects such as the type of walking done by pedestrians, exceptional pedestrian crowding, strong winds, rain, vehicles traffic under footbridges, etc. The resonance phenomenon takes place due to the proximity between the excitation frequencies of the sources and the natural frequencies of the structure, which increase the displacement amplitudes and accelerations, causing discomfort.

In certain situations, pedestrians walking on footbridges can produce excessive vibrations that are uncomfortable and can cause damage to the structure. It is important to emphasize that the study of the phenomenon of excessive vibrations caused by pedestrians on footbridges is not recent. Nevertheless, in recent decades there has been greater demand for this type of structure as a result of significant population increases, both urban and rural. The quality of materials has improved and consequently so have the mechanical properties of the materials used to build these structures, which, by giving priority to aesthetics, tend to become increasingly gracious and light. Accordingly, problems with excessive vibration on footbridges have become more frequent and evident. Since then, a greater susceptibility to excessive vibrations has been observed in these structures when subjected to pedestrian-induced dynamic loads. The other sources of excessive vibrations on footbridges were not taken into account in this work, due to their lower occurrence with regard to the discomfort caused to pedestrians. 
Human-induced vibrations may lead structures to their serviceability limit state, as the human body is quite sensitive to vibrations, according to Wright and Green (1959) and Smith (1988). It is unlikely that these vibrations may damage the structure; in fact, several reports in the literature confirm the absence of structural damage in spite of excessive vibrations. Nonetheless, given the discomfort caused to pedestrians, excessive vibrations on footbridges have been given considerable attention in various codes in developed countries. Several codes, such as BS 5400 (1978), OHBDC (1991), EUROCODE 5 (1997), SIA 160 (1989), CEB (1993), AASHTO (1997) and ISO 10137 (1992), present detailed criteria that include limit values for frequencies and peak acceleration. These codes have design procedures based on defining pedestrian loads; however, there are discrepancies between the accelerations calculated in these equations and the experiments performed on footbridges, as reported by Eyre and Cullington (1985).

With regard to the calculation of pedestrian-induced vibrations on timber footbridges in Brazil, Brazilian code ABNT NBR 7190 (1997) - Wooden Structures Project - does not provide guidelines to determine serviceability limit state. Only succinct recommendations for wooden flooring projects are made in the text of this code. Examining the literature, which contributes to a better understanding of this issue in Brazil, we find, for example, studies of Segundinho (2010a,b).

According to Figueiredo et al. (2008), based on the results of a parametric study of composite footbridges under pedestrian walking loads, it was observed in all investigated structural models that flexural effects were predominant in the fundamental mode of vibration. However it is important to observe that torsional effects are present starting from the second vibration mode, that is, the fundamental mode combined together and become kinds of coupled modes (coupled lateral-torsional modes, etc.). These are mainly excited by the groups or crowds of pedestrians under normal usage. In FIB BULLETIN 32 (2005) suggested that the adding of the lower chord wind bracing allows for an increase of the torsional stiffness and consequently the interest is therefore to increase frequency of torsion in the footbridge.

This paper presents the theoretical, experimental and numerical evaluations in a small-scale model, with the aim of verifying the results of the theoretical and numerical analyses of a full-size timber footbridge. The small-scale model was developed from a $24 \mathrm{~m}$ span and $2 \mathrm{~m}$ width timber footbridge, with two main C60 strength graded ABNT NBR 7190 (1997) timber beams. These criteria were selected because this structure may have problems with excessive vibration, as shown in figure 1, where the theoretical results are given for spans ranging from 5 to $35 \mathrm{~m}, 2 \mathrm{~m}$ width, and C60 strength grade. These timber footbridges were designed for static loads according to ABNT NBR 7190 (1997), and the vertical and lateral first natural frequencies were evaluated. The natural frequencies of the timber footbridge were calculated using the Euler-Bernoulli beam theory (Equation 1), according to EUROCODE 5 (1997).

$$
\mathrm{f}=\frac{\pi}{2 \cdot \mathrm{S}^{2}} \cdot \sqrt{\frac{\mathrm{E} \cdot \mathrm{I}}{\rho \cdot \mathrm{A}}}
$$

Where: $E=$ elastic modulus $\left(\mathrm{N} / \mathrm{m}^{2}\right) ; \mathrm{I}=$ moment of inertia $\left(\mathrm{m}^{4}\right) ; \mathrm{S}=$ span $(\mathrm{m}) ; \mathrm{A}=$ cross-section area $\left(\mathrm{m}^{2}\right)$; and $\rho=$ density $\left(\mathrm{kg} / \mathrm{m}^{3}\right)$.

The calculated frequencies of the first modes are equal to $2.663 \mathrm{~Hz}$ vertically and $0.472 \mathrm{~Hz}$ laterally, that are lower than the limits ( $5.0 \mathrm{~Hz}$ vertically and $2.5 \mathrm{~Hz}$ laterally), according to EUROCODE 5 (1997). In this case, the vibrations are critical, and it is necessary to evaluate the acceleration. 

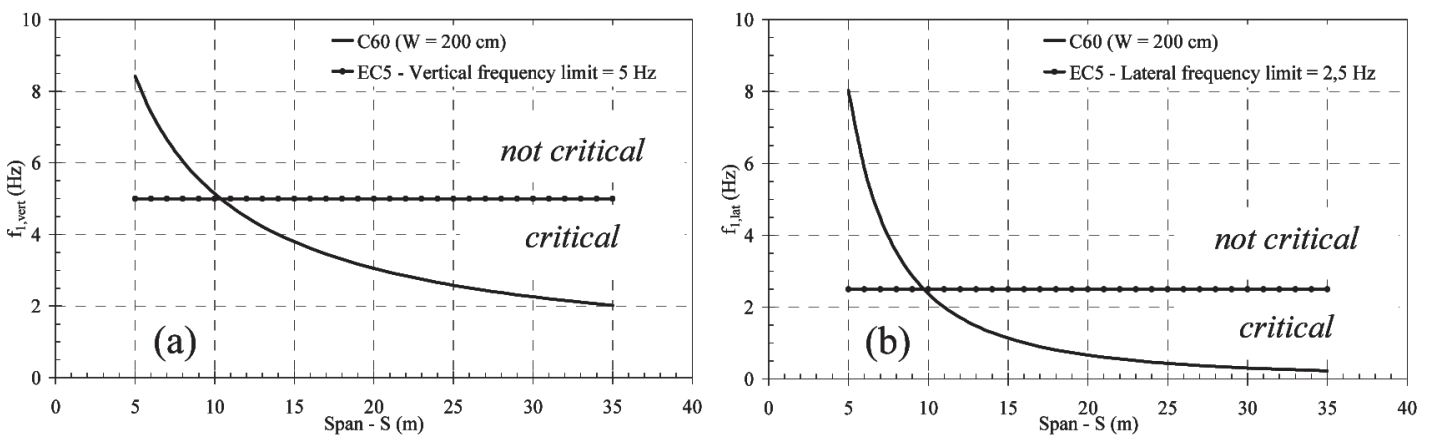

Figure 1. Vertical (a) and lateral (b) frequencies in relation to footbridge span

The tests in the small-scale model were carried out in two ways: 1) static, by applying concentrated load on mid-span; 2) dynamic, using an impact hammer and accelerometer in order to obtain the modal parameters from the frequency response function of the small-scale model. The numerical analysis of the small-scale model was carried out using the finite elements method, by means of the structural analysis in the software SAP2000 (2005) version 10.0.7.

\section{MATERIALS AND METHODS}

\section{Small-scale model construction}

The model was made using Ocotea spectabilis wood specie. The mean value of modulus of elasticity of the timber member, determined through static bending tests, were equal to $\mathrm{E}=6904 \mathrm{MPa}$. The means values for flexural strength and density at $12 \%$ moisture are equals to $66.8 \mathrm{MPa}$ and 650 $\mathrm{kg} / \mathrm{m}^{3}$, respectively.

The preparation of the small-scale model involved the study of aspects related to the reproduction of the geometric and physical characteristics of the real footbridge. Figure 2 shows the dimensions of the small-scale model timber footbridge. The span and width of the model were reduced in a geometric scale (1:4). The dimensions of the structural elements (beams and boards) were scaled down so that the obtained vertical-direction natural vibration frequency was similar to that of the real footbridge. This similarity was not applied to lateral vibration, as it would make the main beams exceedingly thin, among other problems. Thus, it was chosen to use the 1:4 scale for the width of beams, and the height were determined to obtain the vertical vibration frequency as in the real footbridge, without the need to add mass to the system. Figure 2 and 3 show the dimensions and pictures of the small-scale model. All wooden members were marked and pre-drilled for the placement of nails featuring heads with 3.0 $\mathrm{mm}$ diameter and $62.1 \mathrm{~mm}$ length. 


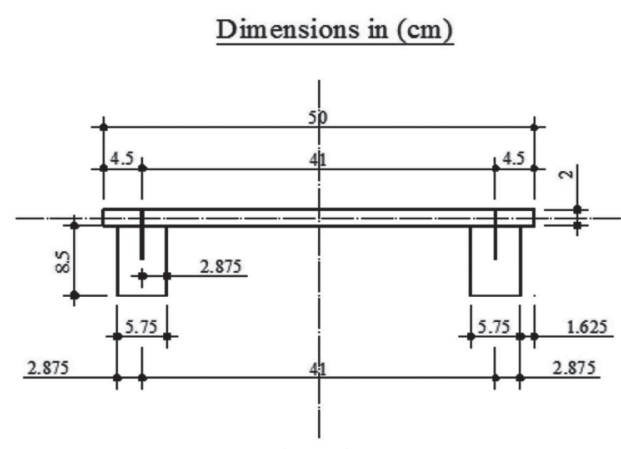

Elevation

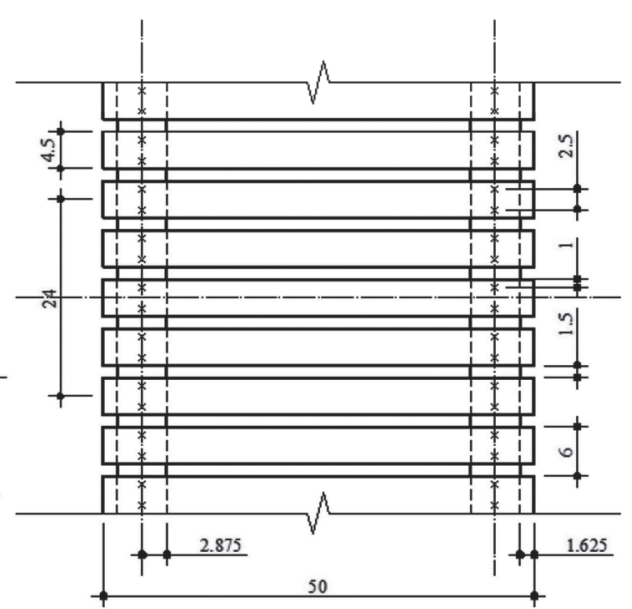

$\underline{\text { Plan }}$

Figure 2. Elevation and plan of the small-scale model ( $\mathrm{Span}=6 \mathrm{~m}$ and Width $=0.5 \mathrm{~m})$

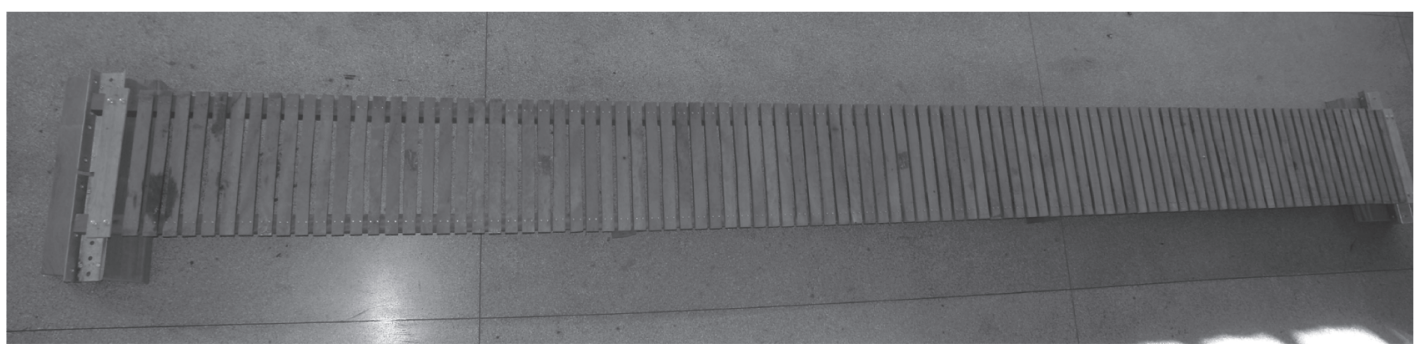

Figure 3. Small-scale model timber footbridge

\section{Static test}

The model bending stiffness in the vertical and lateral directions were determined through static tests. These values were used later to determine the theoretically natural frequencies. The static test was done using weights placed on the mid-span of the small-scale model, and measuring displacements in the same point with dial indicator. The values obtained were equal to $41,789 \mathrm{~N} \cdot \mathrm{m}^{2}$ (vertical direction) and $74,337 \mathrm{~N} \cdot \mathrm{m}^{2}$ (lateral direction).

\section{Dynamic test}

This test measured the natural frequencies regarding the $1^{\text {st }}, 2^{\text {nd }}$ and $3^{\text {rd }}$ modes of vibration in the vertical direction and the $1^{\text {st }}$ mode of vibration in the lateral direction, by means of their respective FRFs (Frequency Response Functions). The accelerometer was placed in the points with greatest displacement amplitude of the modes of vibration of a simply-supported beam, corresponding to first three modes, in the vertical and lateral directions, three test at the same point, total thirty trials. Ten excitations were made at these same points, shown in figure 4, using an impact hammer which introduced an approximate force of $500 \mathrm{~N}$ in the vertical direction e $1000 \mathrm{~N}$ in the lateral direction. 


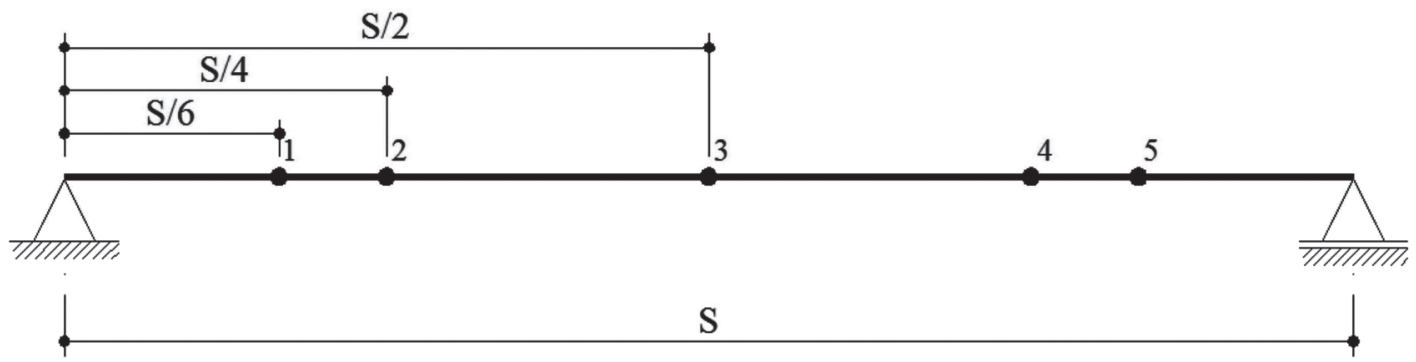

Figure 4. Points of excitation and response for vertical and lateral directions of the model

Figure 5 shows the dynamic test, for the particular case of excitation and frequent measurement at the same point, for both directions. When we change the direction of the impact hammer the accelerometer is rotated in the same direction.
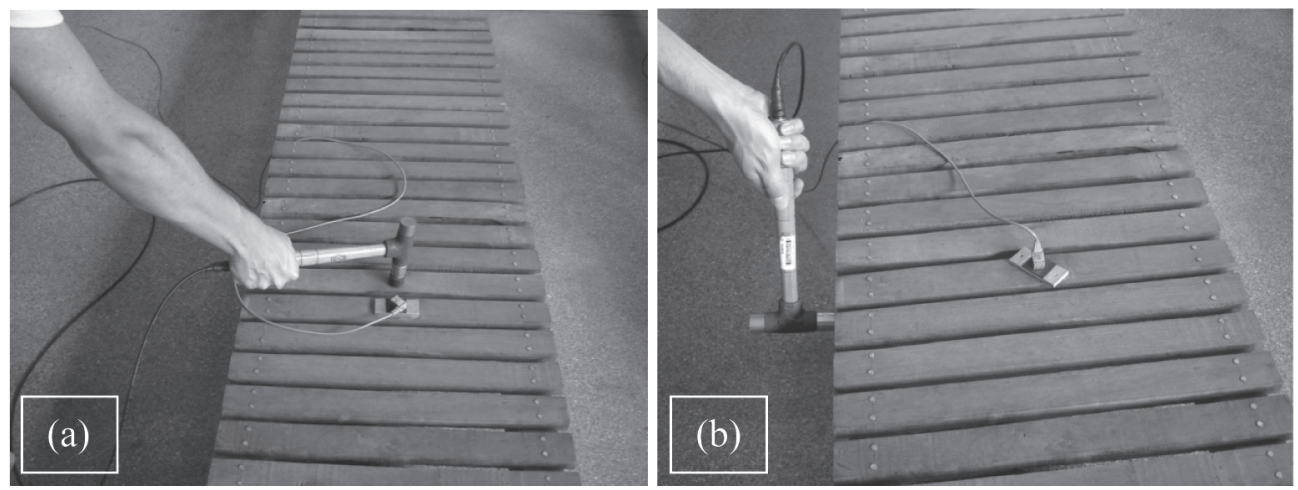

Figure 5. Dynamic test of the small-scale model in the (a) vertical and (b) lateral directions

A uniaxial resistive accelerometer model AS-2GA (Kyowa) was used to measure the dynamic response of the model. An impact hammer model 2303 (Endevco Corporation) was used for excitation. Excitation and response signals were conditioned, followed by analog-to-digital conversion (ADC) using an NI USB 6009 (National Instruments) device.

\section{Numerical modeling}

The small-scale model timber footbridge was modeled by incorporating all structural details according to the design concept, figure 2. A numerical analysis of the small-scale model timber footbridge was carried out with SAP2000 (2005) structural analysis software, using the general quadrilateral shell finite elements for beams and boards. This software can be used for linear and non-linear, static and dynamic analyses of a 3D model of the structure. Also, it is possible to using shell elements. It was assumed pinned connections between beams and foundation, but with a possibility to slide freely in the longitudinal direction i.e. along the timber footbridge longitudinal axis, and rigidly connected together at the intersection points between beams and boards, based on its original design assumptions. Within the timber footbridge, member connections are taken as rigid. The finite element mesh (dimensions of $45.0 \mathrm{~mm} \times 2.25 \mathrm{~mm}$ and $41.0 \mathrm{~mm} \times 2.25 \mathrm{~mm}$ ) for the timber boards was defined in the horizontal plane and timber beams were modeled by a mesh (dimensions of $30.0 \mathrm{~mm} \times 42.5 \mathrm{~mm}$ ) in the vertical plane. The thickness attributed to each element represents the true thickness of the member. The dimensions of the finite element mesh were set using form factor one to four. The modal damping coefficient $\zeta$ adopted in the numerical modeling was equal to 0.010 considering structures without mechanical joints, according to EUROCODE 5 (1997). 


\section{RESULTS AND DISCUSSION}

First, the theoretical first natural frequencies for the vertical $\left(\mathrm{f}_{\text {vert, } \mathrm{Tl}}\right)$ and lateral $\left(\mathrm{f}_{\mathrm{lat}, \mathrm{T1}}\right)$ directions were obtained using the Euler-Bernoulli beam theory, equation 1. In this case, the mass of model $(69.2 \mathrm{~kg})$, modulus of elasticity, and dimensions of the timber beams (boards are not considered) were used to calculate bending stiffness. The first natural frequencies in the vertical $\left(\mathrm{f}_{\text {vert, T2 }}\right)$ and lateral $\left(\mathrm{f}_{\text {lat,T2 }}\right)$ directions were also determined using the experimental static bending stiffness values of the small-scale model. Table 1 shows the results obtained for both cases.

Table 1. Theoretical natural frequencies of the small-scale model

\begin{tabular}{c|c|c|c}
\hline Direction & Mode & \multicolumn{2}{|c}{ Frequencies $(\mathrm{Hz})$} \\
\hline \multirow{2}{*}{ Vertical } & \multirow{2}{*}{1} & $\mathrm{f}_{\text {vert,T1 }}$ & $\mathrm{f}_{\text {vert,T2 }}$ \\
\cline { 3 - 4 } & & 2.453 & 2.626 \\
\hline \multirow{2}{*}{ Lateral } & \multirow{2}{*}{1} & $\mathrm{f}_{\text {lat,T1 }}$ & $\mathrm{f}_{\mathrm{lat}, \mathrm{T} 2}$ \\
\cline { 3 - 4 } & & 1.659 & 3.443 \\
\hline
\end{tabular}

The FRFs of the model were obtained in two different ways. First, the continuous beam formulation was applied and the theoretical system FRFs were obtained for one excitation and one linear response in different points, according to McConnell and Varoto (2008), from the experimental values of bending stiffness. The experimental FRFs were also obtained from the dynamic tests. Figure 6 shows the $\mathrm{H}_{15}$ transfer FRFs (excitation in point 1 and response in point 5), which were obtained using beam theory and experimental results for the vertical direction.

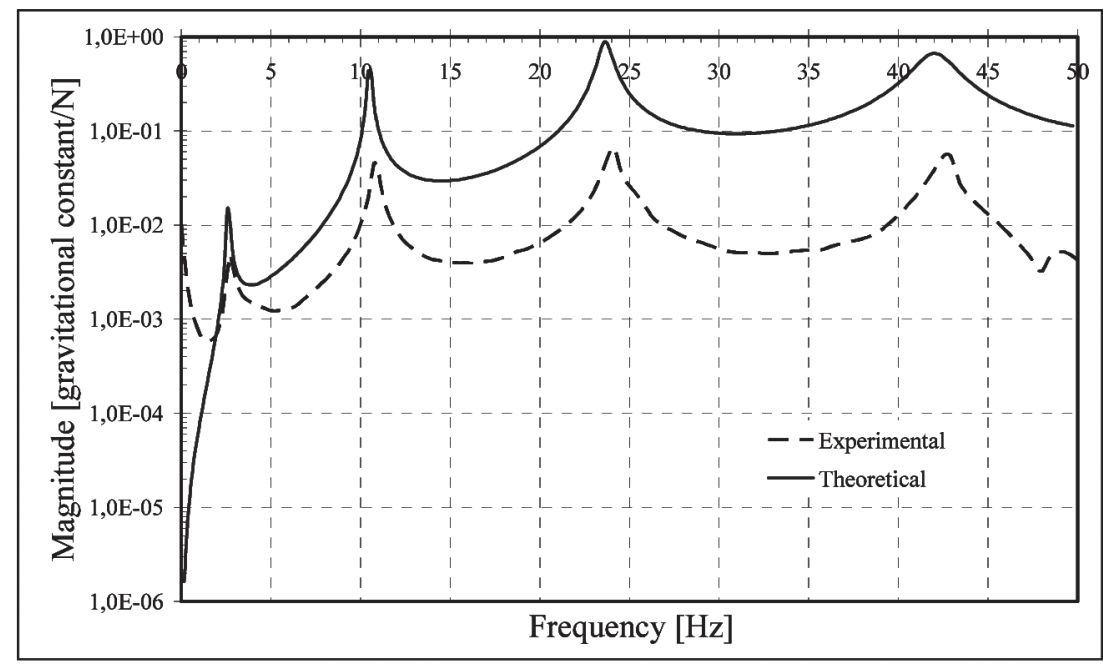

Figure 6. $\mathrm{H}_{15}$ transfer FRF for the vertical direction of the small-scale model

Table 2 shows the results for the natural frequencies obtained from the theoretical $\left(\mathrm{f}_{\text {vert, } \mathrm{T3}}\right.$ and $\left.\mathrm{f}_{\text {lat,T3}}\right)$ and experimental $\left(\mathrm{f}_{\text {vert,exp }}\right.$ and $\mathrm{f}_{\text {latexp }}$ ) FRFs and their respective modal damping coefficients. The modal parameters were identified using the peak-picking technique, according to $\mathrm{He}$ and $\mathrm{Fu}(2001)$, from the average of ten experimental FRFs for each natural frequency of the model. 
Table 2. Experimental natural frequencies and modal damping of the small-scale model

\begin{tabular}{c|c|c|c|c}
\hline Direction & Mode & $\mathrm{f}_{\text {vert,T3 }}(\mathrm{Hz})$ & $\mathrm{f}_{\text {vert,exp }}(\mathrm{Hz})$ & $\zeta(\%)$ \\
\hline \multirow{3}{*}{ Vertical } & 1 & 2.627 & 2.734 & 5.73 \\
\cline { 2 - 5 } & 2 & 10.506 & 10.767 & 1.86 \\
\cline { 2 - 5 } & 3 & 23.638 & 24.165 & 1.27 \\
\hline Direction & Mode & $\mathrm{f}_{\text {lat,T3 }}(\mathrm{Hz})$ & $\mathrm{f}_{\text {lat,exp }}(\mathrm{Hz})$ & $\zeta(\%)$ \\
\hline Lateral & 1 & 3.503 & 7.520 & 7.80 \\
\hline
\end{tabular}

The experimental damping values for the first mode of vibration in the vertical and lateral directions are five to eight times higher the values recommended by EUROCODE 5 (1997). With regard to vertical modal damping of the second to third modes shown in table 2, they were one to two times higher than the recommended values for timber structures, according to EUROCODE 5 (1997). The damping decreases the amplitude of the vibrations can reach high vibration levels user's comfort and especially its safety, according to Figueiredo et al. (2008).

Table 3 shows the numerical natural frequencies $\left(\mathrm{f}_{\text {vert,N1 }}\right.$ and $\mathrm{f}_{\text {lat,N1 }}$ ) corresponding to the modes of vibration when one rigid node is included in the connection between the beams and boards. The natural frequencies $\left(\mathrm{f}_{\text {vert, } \mathrm{N} 2}\right.$ and $\mathrm{f}_{\text {lat, } \mathrm{N} 2}$ ) corresponding to the second model considering two rigid nodes in the connection between the beams and boards are also show in table 3. Figure 7 shows the first three modes of vibration of the model in the vertical direction.

Table 3. Numerical natural frequencies of the small-scale model

\begin{tabular}{c|c|c|c}
\hline \multirow{2}{*}{ Direction } & \multirow{2}{*}{ Mode } & \multicolumn{2}{|c}{ Frequencies $(\mathrm{Hz})$} \\
\cline { 3 - 4 } & & $\mathrm{f}_{\text {vert, N1 }}$ & $\mathrm{f}_{\text {vert, N2 }}$ \\
\hline \multirow{3}{*}{ Vertical } & 1 & 2.675 & 2.824 \\
\cline { 2 - 4 } & 2 & 10.668 & 11.260 \\
\cline { 2 - 4 } & 3 & 23.867 & 25.178 \\
\hline Direction & Mode & $\mathrm{f}_{\text {lat,N1 }}$ & $\mathrm{f}_{\text {lat }, \mathrm{N} 2}$ \\
\hline Lateral & 1 & 3.368 & 13.272 \\
\hline
\end{tabular}

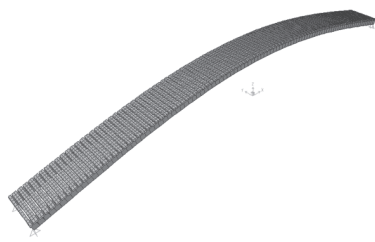

a) Mode 1

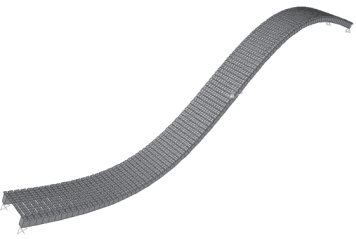

b) Mode 2

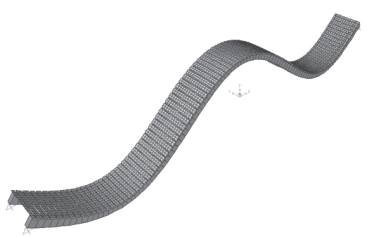

c) Mode 3

Figure 7. Modes of vibration in the vertical direction of the small-scale model

The analysis of the results shown in tables 4 and 5 are restricted to the frequencies relative to the first mode of vibration for the vertical and lateral directions, which is the parameter used to verify serviceability limit state on footbridges. Table 4 shows the theoretical, experimental and numerical values regarding the natural frequencies of the model. Table 5 contains the ratios of the theoretical and numerical values to the value obtained experimentally. 
Table 4. Natural frequencies of the small-scale model

\begin{tabular}{|c|c|c|c|c|c|c|c|}
\hline \multirow{2}{*}{ Direction } & \multirow{2}{*}{ Mode } & \multicolumn{6}{|c|}{ Frequency $(\mathrm{Hz})$} \\
\hline & & \multicolumn{3}{|c|}{ Theoretical } & Experimental & \multicolumn{2}{|c|}{ Numerical } \\
\hline \multirow{2}{*}{ Vertical } & \multirow{2}{*}{1} & $f_{\text {vert }, T 1}$ & $f_{\text {vert }, T 2}$ & $f_{\text {vert }, T 3}$ & $f_{\text {vertexp }}$ & $\mathrm{f}_{\text {vert }, \mathrm{N} 1}$ & $\mathrm{f}_{\mathrm{vert}, \mathrm{N} 2}$ \\
\hline & & 2.453 & 2.626 & 2.627 & 2.734 & 2.675 & 2.824 \\
\hline \multirow{2}{*}{ Lateral } & \multirow{2}{*}{1} & $\mathrm{f}_{\text {lat,T1 }}$ & $\mathrm{f}_{\text {lat, } 12}$ & $\mathrm{f}_{\text {lat,T3 }}$ & $f_{\text {latexp }}$ & $\mathrm{f}_{\mathrm{lat}, \mathrm{N} 1}$ & $\mathrm{f}_{\text {lat,N2 }}$ \\
\hline & & 1.659 & 3.443 & 3.503 & 7.520 & 3.368 & 13.272 \\
\hline
\end{tabular}

Table 5. Ratio of the natural frequencies of the small-scale model

\begin{tabular}{|c|c|c|c|c|c|c|}
\hline Direction & Mode & & & Ratio & & \\
\hline \multirow{3}{*}{ Vertical } & \multirow{3}{*}{1} & $f_{\text {vert T1 }}$ & $f_{\text {vert,T2 }}$ & $f_{\text {vert.T3 }}$ & $f_{\text {vert,N1 }}$ & $f_{\text {vert.N2 }}$ \\
\hline & & $\overline{f_{\text {vert,exp }}}$ & $f_{\text {vert,exp }}$ & $f_{\text {vert,exp }}$ & $\overline{f_{\text {vert,exp }}}$ & $f_{\text {vert,exp }}$ \\
\hline & & 0.90 & 0.96 & 0.96 & 0.98 & 1.03 \\
\hline \multirow{3}{*}{ Lateral } & \multirow{3}{*}{1} & $\mathrm{f}_{\text {latT1 }}$ & $f_{\text {lat,T2 }}$ & $f_{\mathrm{lat}_{\mathrm{T} 3}}$ & $f_{\text {latN11 }}$ & $\mathrm{f}_{\mathrm{lat}, \mathrm{N} 2}$ \\
\hline & & $\overline{f_{\text {lat,exp }}}$ & $f_{\text {lat,exp }}$ & $\overline{f_{\text {lat,exp }}}$ & $\overline{f_{\text {lat,exp }}}$ & $\overline{f_{\text {lat,exp }}}$ \\
\hline & & 0.22 & 0.46 & 0.47 & 0.45 & 1.76 \\
\hline
\end{tabular}

In the case of the vertical direction, the theoretical and numerical values of the frequencies shown in Table 5 are close to the experimental value, which indicates that the theoretical formulation and numerical modeling used adequately represent the real behaviour of the model. Therefore, for the design of fullscale simply-supported timber footbridges can be used the Euler-Bernoulli formulation, considering just the flexural stiffness of the beams.

However, the same observation cannot be made concerning lateral direction. As shown in tables 4 and 5, the first natural frequency in the lateral direction obtained experimentally is higher than the value calculated using the Euler-Bernoulli formula (considering just the flexural stiffness of the beams or the flexural stiffness evaluated through static test), and have intermediate values when compared to those obtained numerical modeling. The numerical analysis in the lateral direction must be improved with the use of rotational spring finite elements that can represent the stiffness of the connection between beams and boards, based on using the software SAP2000 (2005).

\section{CONCLUSIONS}

The main conclusion drawn from the theoretical, numerical and experimental results of the smallscale model, with regard to natural frequency, is that the Euler-Bernoulli formula is suitable to calculate the first natural frequency in the vertical direction for simply-supported timber footbridges, considering only the bending stiffness of the beams. As the deck boards contributes little to vertical stiffness. It can be expected that the vertical direction vibrations of real structures built with similar configurations can be evaluated using the Euler-Bernoulli equation, considering only the bending stiffness of the main beams. However, there are discrepancies between experimental, theoretical and numerical values for the lateral direction. Contrary to the previous case, considering only the inertia of the main beams, ignoring the bending stiffness of the deck boards and the effect of the connection between boards and beams, leads to excessively conservative calculation. Thus, special attention must be given to the evaluation of bending stiffness in the lateral direction when applying the Equation 1. 
One of the great difficulties in this case is to evaluate bending stiffness of the structure in the lateral direction, which is affected by the form of the connection between the boards and main beams. As shown in Tables 4 and 5, the first natural frequency in the lateral direction obtained experimentally have intermediate values when compared to those obtained numerically and is higher than the value calculated using the Euler-Bernoulli formula.

Another important point is related to the fact that the experimental results obtained throughout the investigation showed that the design standards could produce safe values same they are based on simplified models. This paper presents a contribution for the evaluation of a simply-supported timber footbridge's structural behaviour due to flexural effects (predominant in the fundamental mode of vibration).

\section{ACKNOWLEDGMENTS}

To CNPq (National Council for Scientific and Technological Development - Brazil) and CAPES (Coordination for the Improvement of Higher Education Personnel - Brazil) for the scholarship and financial support given to this research.

\section{REFERENCES}

AASHTO. 1997. Guide specifications for design of pedestrian bridges. American Association of State, Highway and Transportation Officials, August. 21p.

ABNT. 1997. Associação Brasileira de Normas Técnicas. NBR 7190, Projeto de Estruturas de Madeira, Rio de Janeiro, Brasil. 107p.

BS 5400. 1978. Steel, Concrete and Composite Bridges-Part 2: Specification for Loads. Appendix C: Vibration Serviceability Requirements for Foot and Cycle Track Bridges. British Standards Association, London, U.K. 46p.

CEB-FIP MODEL CODE 1990. 1993. Design Code. Comite' Euro-Internatinal du Be'ton, Thomas Telford Ltd, London, U.K. 437 p.

EUROCODE 5. 1997. Design of Timber Structures-Part 2: Bridges. ENV 1995-2: 2006, European Committee for Standardization, Brussels, Belgium. 45p.

Eyre, R.; Cullington, D. W. 1985. Experience with vibration absorbers on footbridges. TRRL Research Report No. 18, Transport and Road Research Laboratory, Crowthrone, England.

Fib Bulletin No. 32. 2005. Guidelines for the design of footbridges: Guide de good practice. Federal Institute of Technology Lausanne, International Federation of Structural Concrete, Lausanne, Switzerland. $160 \mathrm{p}$.

Figueiredo, F. P.; Silva, J. G. S.; Vellasco, P. C. G. S.; Lima, L. R. O.; Andrade, S. A. L. 2008. A parametric study of composite footbridges under pedestrian walking loads. Engineering Structures 30: 605-615.

He, J.; Fu, Z.F. 2001. Modal Analysis. 2. ed., Butterworth-Heinemann, Oxford, England. 304p.

ISO. 10137. 1992. ISO 10137. Bases for Design of Structures-Serviceability of Buildings Against Vibrations. International Standardization Organization, Geneva, Switzerland. 32p. 
Mcconnell, K. G.; Varoto, P. S. 2008. Vibration testing: theory and practice. 2. ed., Hoboken: John Wiley \& Sons, New York, U.S.A. 652p.

OHBDC. 1991. Ontario Highway Bridge Design Code. Highway Engineering Division. Ministry of Transportation and Communication, 3. ed., Ontario, Canada.

SAP2000. 2005. Integrated Finite Element Analysis and Design of Structures. Computers and Structures, Inc., Berkeley, California, U.S.A. 415p.

Segundinho, P. G. A. 2010a. Study of pedestrian-induced vibrations on timber footbridges. Ph.D. Thesis in Structural Engineering, São Carlos School of Engineering of the University of São Paulo, São Carlos, Brazil. May. 361 p.

Segundinho, P. G. A. 2010b. Study of pedestrian-induced vibrations on timber footbridges. Maderas. Ciencia y tecnología 12 (2):149-149.

SIA 160. 1989. Action on structures. Swiss Society of Engineers and Architects. SIA Standard 160, Zürich, Switzerland. 114p.

Smith, J. W. 1988. Vibrations in Structures. Applications in Civil Engineering Design, Chapman \& Hall, London, U.K.

Wright, D. T.; Green, R. 1959. Human sensitivity to vibration. Report No. 7, Queen's University, Kingston, Ontario, Canada. 23p. 